Dedicated to Prof. Billy E. Rhoades on the occasion of his $90^{\text {th }}$ anniversary

\title{
On the geometry of $b$-distances and the fixed points of mappings
}

\section{Mitrofan M. CHOBAN}

\section{ABSTRACT.}

In the present article we study the geometrical configuration of $b$-perturbation of the norm of the normed space. The notion of $b$-metric is important in the solving of the fixed point problem.

Acknowledgments. The author is grateful to Professor Vasile Berinde for interesting problems and valuable suggestions.

\section{REFERENCES}

[1] Alexandroff, P. and Urysohn, P., Une condition nécésare et suffisantepour qu'une classe (L) soit une classe (D), C. R. Acad. Paris, 177 (1923), 1274-1276

[2] Altun, I., Sola, F. and Simsek, H., Generalized contractions on partial metric spaces, Topol. Appl., 157 (2010), 2778-2785

[3] Arhangel'skii, A. V., Mappings and spaces, Uspehi Matem. Nauk, 21 (1966), No. 4, 133-184, (English translation: Russian Math. Surveys, 21 (1966), No. 4, 115-162

[4] Bakhtin, I. A., The contraction mapping principle in almost metric spaces, Funct. Anal., Ulianovskii Gosud. Pedag. Inst., 30 (1989), 26-37

[5] Berinde, V., Error estimates for a class of $(\delta, \varpi)$-contractions, Babeş-Bolyai Univ. Facul. Math. Comput. Sci. Res. Sem., Preprint No. 3, 1994, 3-10

[6] Berinde, V. and Choban, M., Remarks on some completeness conditions involved in several common fixed point theorems, Creat. Math. Inform., 19 (2010), No. 1, 1-10

[7] Berinde, V. and Choban, M.,Generalized distances and their associate metrics. Impact on fixed point theory, Creat. Math. Inform., 22 (2013), No. 1, 23-32

[8] Bukatin, M., Kopperman, R., Matthews, S. and Pajoohesh, H., Partial metric spaces, Amer. Math. Monthly, 116 (2009), No. 8, 708-718

[9] Cauty, R., Solution du probleme de point fixe de Schauder, Fund. Math., 170 (2001), No. 3, 231-246

[10] Chittenden, E. W., On the equivalence of écart and voisinage, Trans. Amer. Math. Soc., 18 (1917), 161-166

[11] Choban, M. M., Fixed points for mappings defined on pseudometric spaces, Creat. Math. Inform., 22 (2013), No. 2, 173-184

[12] Choban, M. M., Selections and fixed points theorems for mapping defined on convex spaces, ROMAI J., 10 (2014), No. 2, 11-44

[13] Choban, M. M., Fixed points for mappings defined on generalized gauge spaces, Carpathian J. Math., 31 (2015), No. 3, 313-324

[14] Choban, M. M., Fixed points of mappings defined on spaces with distance, Carpathian J. Math., 32 (2016), No. 2, 173-188

[15] Choban, M. M. and Berinde, V., A general concept of multiple fixed point for mappings defined on spaces with a distance, Carpathian J. Math., 33 (2017), No. 3, 275-286

[16] Choban, M. M. and Berinde, V., Two open problems in the fixed point theory of contractive type mappings on quasimetric spaces, Carpathian J. Math., 33 (2017), No. 2, 169-180

Received: 14.06.2019; In revised form: 07.04.2020; Accepted: 14.04.2020

2010 Mathematics Subject Classification. 54H25, 54E15, 54H13, 12J17, 54E40.

Key words and phrases. quasi-metric, distance, b-bifurcation of the norm, fixed point. 
[17] Choban, M. M. and Calmutchi, L. I., Fixed points theorems in multi-metric spaces, Annals of the Academy of Romanian Scientists, Series on Mathematics and its Applications 3 (2011), 46-68

[18] Choban, M. M. and Calmutchi, L. I., Fixed points theorems in E-metric spaces ROMAI J. 6 (2010), No. 2, 83-91

[19] Czerwik, S., Fixed Points Theorems and Special Solutions of Functional Equations, Katowice, 1980

[20] Engelking, R., General Topology, PWN, Warszawa, 1977

[21] Frink, A. H., Distance functions and the metrization problem, Bull. Amer. Math. Soc., 43 (1937), 133-142

[22] Granas, A. and Dugundji, J., Fixed point theory, Springer, 2003

[23] Hitzler, P. and Seda, A. K., Mathematical Aspects of Logic Programming Semantics, Chapman \& Hall/CRC Studies in Informatic Series, CRC Press, 2011

[24] Hitzler, P. and Seda, A. K., Dislocated topologies, J. Electr. Engin., 51 (12) (2000), 3-7

[25] Karapinar, E., A Short Survey on Dislocated Metric Spaces via Fixed-Point Theory, In: J. Banas, M. Jleli, M. Mursaleen, B. Samet, C. Vetro (eds.), Advances in Nonlinear Analysis via the Concept of Measure of Noncompactness, Springer, 2017, 457-483

[26] Matthews, S. G., Partial metric topology, Annals of the New York Academy of Sciences 728, Proceedings of the 8th Summer Conference on General Topology and Applications 1994, 183-197

[27] Nedev, S. I., o-metrizable spaces, Tr. Mosk. Mat. Obs., 24 (1971), 201-236 English translation: Trans. Moscow Math. Soc., 24 (1974), 213-247

[28] Nedev, S. and Choban, M., On the theory of o-metrizable spaces, I, Vestnik Moskovskogo Universiteta, 1 (1972), 8-15 English translation: Moscow University Mathematics Bulletin, 27 (1973), No. 1-2, 5-9

[29] Nedev, S. and Choban, M., On the theory of o-metrizable spaces, II, Vestnik Moskovskogo Universiteta, 2 (1972), 10-17 English translation: Moscow University Mathematics Bulletin, 27 (1973), No. 1-2, 65-70

[30] Nedev, S. and Choban, M., On the theory of o-metrizable spaces, III, Vestnik Moskovskogo Universiteta, 3 (1972), 10-15 English translation: Moscow University Mathematics Bulletin, 27 (1973), No. 3-4, 7-11

[31] Niemytzki, V., On the third axiom of metric spaces, Trans Amer. Math. Soc., 29 (1927), 507-513

[32] Niemytzki, V., Uber die Axiome des metriohen Raumes, Math. Ann., 104 (1931), 666-671

[33] Oltra, S. and Valero, O., Banach's Fixed Point Theorem for Partial Metric Spaces, Rend. Istit. Mat. Univ. Trieste, XXXVI (2004), 17-26

[34] Rus, I. A., Petrusel, A. and Petrusel, G., Fixed point theory, Cluj University Press, Cluj-Napoca, 2008

\section{TIRASPOL STATE UNIVERSITY}

FACUlTY OF PHYSiCS, MATHEMATICS AND INFORMATION TECHNOLOGIES

GHENADie IABlocichin 5, 2069, ChişinăU, RepUbliC OF MOLdOVA

Email address: mmchoban@gmail.com 